\title{
Back to the basics: deworming HIV-1-infected individuals
}

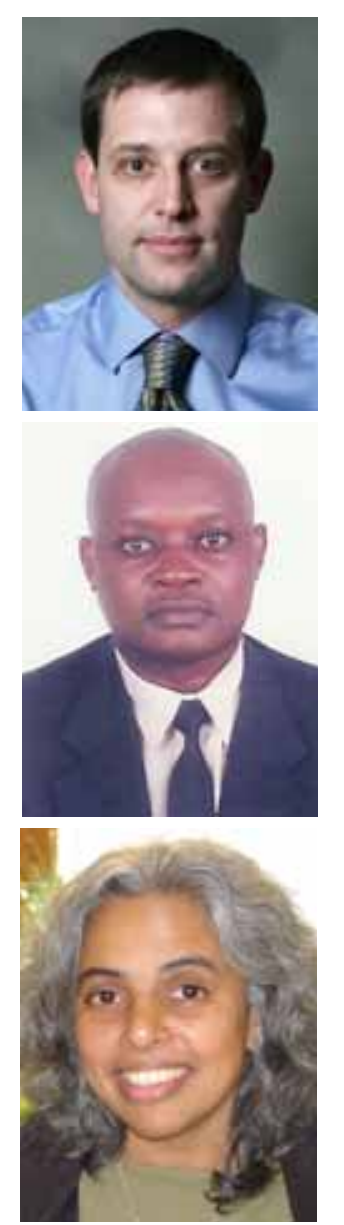

Judd L Welson', Bensan $O$ Singa \& GraceJdm-Stevert

${ }^{\dagger}$ Author for correspondence University of Washington, Department of M edicine, Seattle, WA, USA

Tel.: +1 206543 4278;

Fax: +1 206543 4818;

walson@u.washington.edu

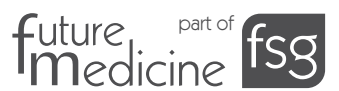

\section{‘...while a ntiretroviral thera py}

scale-up is a critical priority in the global fight aga inst HIV/AIDS, it is impera tive to identify additional

strategies to dec rease HIV-1 disea se progression and transmission.'

The H IV -1/AID S pandemic has been the catalyst for an incredible series of breakthroughs in molecular biology, immunology and drug development. The pace and success of discovery continue as the pandemic enters its third decade. Despite many innovations and discoveries, the grim reality of the pandemic is equally astounding. An effective vaccine candidate remains elusive, antiretroviral resistance continues to keep pace with drug discovery, the incidence and prevalence of HIV-1 continues to rise in some areas and more than $70 \%$ of those needing antiretroviral therapy (ART) do not yet have access to these drugs [1].

Expansion of access to ART for HIV/AIDS has become a global priority. While ART is the most effective intervention for the treatment of HIV -1, the majority of those in need of ART live in areas of the world where access is limited. Although significant funding has been mobilized to provide ART, implementation of ART programs remains a major challenge owing to limitations in funding, manpower and physical infrastructure [2,3]. Current targets for the scale-up of ART in resource-limited settings call for a tenfold expansion of healthcare services over the next several years [4]. Even if these ambitious goals are met, they will still fall short of providing care for the majority of those who are eligible for ART in many countries. Thus, while ART scale-up is a critical priority in the global fight against H IV/AID S, it is imperative to identify additional strategies to decrease HIV-1 disease progression and transmission.

O ne promising area of research focuses on the treatment of helminth coinfection, a hypothesis first suggested by Bentwich et al. [5]. Given that as many as half of all individuals living in Africa are infected with at least one species of helminth and the significant geographic overlap in these infections, the public health significance of deworming among HIV-1-infected individuals may be substantial [6,7]. Intriguing data are emerging suggesting that treatment of helminth coinfection in HIV-1-infected individuals may alter H IV-1 disease progression. In addition, it is possible that reductions in plasma H IV-1 RN A following helminth eradication may impact infectivity and HIV-1 transmission.

We recently published a systematic review in the Cochrane Library evaluating data from one randomized trial and several observational studies that noted possible decreases in H IV -1 viral load following treatment of helminth coinfection [8]. There have now been three randomized, controlled trials (RCTs) evaluating the effects of deworming on markers of HIV-1 disease progression. The first, conducted in Zimbabwe, evaluated the treatment of schistosomiasis in adults with HIV-1 not on ART. The results demonstrated an increase in plasma HIV-1 RNA $\left(0.21 \log _{10}\right.$ copies $\left./ \mathrm{ml}\right)$ in those randomized to deferred treatment, compared with almost no change in those receiving early antischistosomal therapy [9]. In Tanzania, treatment of HIV-1-infected individuals with lymphatic filariasis resulted in a significant reduction in plasma HIV-1 RNA (0.34 $\log _{10}$ copies $\left./ \mathrm{ml}\right)$ in those receiving diethylcarbamazine as compared with placebo [10]. In another RCT conducted in Kenya, we demonstrated that H IV-1 and Ascariscoinfected adults randomized to albendazole had a significant increase in CD4 counts of 109 cells $/ \mathrm{mm}^{3}$, and a trend towards a $0.54 \log _{10}$ reduction in plasma viral load after 3 months when compared to those receiving deferred therapy [11]. An increase in CD 4 count of over 100 cells $/ \mathrm{mm}^{3}$ in 12 weeks, such as that observed in our study of Ascaris-coinfected individuals, is greater than that seen with nonantiretroviral interventions and is comparable to that seen with early ART [12].

M odeling studies suggest that a reduction in viral load of the magnitude observed in these studies may reduce the time to the development of AIDS by as much as 3.5 years [13]. Such a reduction in viral load may also significantly 
reduce transmission rates. Prior studies have shown heterosexual transmission rates to more than double with each log increase in plasma H IV -1 RN A [14]. In the only available study that has evaluated the effect of helminth coinfection on HIV - 1 transmission, there was a sevenfold increased risk of mother-to-child transmission among mother-infant pairs in which the mother had documented helminth infection in pregnancy when compared with mothers without helminths [15].

'Given that as ma ny a s half of all
individuals living in Afric a are infected
with at lea st one species of helminth...
the public health signific ance of
deworming a mong HIV-1-infec ted
individuals may be substa ntial.'

In addition to possible effects on markers of disease progression and infectivity, emerging data suggest that helminth infection may also affect susceptibility to HIV-1 infection, the development of immune reconstitution inflammatory syndrome and the possible response to any proposed HIV-1 vaccine [16-18]. Despite these promising observations, research into the area of helminth and H IV -1 coinfection remains limited by lack of interest and lack of funding.

Approximately 2 billion people are infected with at least one species of soil-transmitted helminth, with the vast majority of these infections occurring in Sub-Saharan Africa where the HIV-1/AIDS pandemic is most severe. Identifying practical and inexpensive interventions to delay immunosuppression and reduce infectivity should be a major focus of HIV-1 research efforts. Given the potential impact of deworming on HIV-1 progression and infectivity, additional research in this area should be a priority.

The future of HIV-1 therapy will certainly include newer and more effective antiretroviral drugs. In addition, there is hope that an effective vaccine can be developed. At the sametime, it is important that we not neglect the evaluation of potentially feasible interventions, such as helminth eradication, which may delay HIV-1 progression or decrease the spread of HIV-1. The future of HIV treatment must combine innovation and discovery with a package of diverse interventions that can be rapidly implemented to stem the H IV-1 epidemic.

Financial \& competing interests disclosure The authors have no relevant affiliations or financial involvement with any organization or entity with a financial interest in or financial conflict with the subject matter or materials discussed in the manuscript. This includes employment, consultancies, honoraria, stock ownership or options, expert testimony, grants or patents received or pending, or royalties

$\mathrm{N}$ o writing assistance was utilized in the production of this manuscript.

\section{Bibliography}

1. Ojikutu B: Introduction: the realities of antiretroviral therapy rollout: overcoming challenges to successful programmatic implementation. J. Infect. D is. 196, S445-S448 (2007).

2. Cleary SM, M clntyre D, Boulle AM : The cost-effectiveness of antiretroviral treatment in Khayelitsha, South Africa: a primary data analysis. Cost-effectiveness and resource allocation. Cost Eff. Resour. Alloc. 4, 20 (2006).

3. Goldie SJ, Yazdanpanah Y, Losina E et al.: Cost-effectiveness of H IV treatment in resource-poor settings: the case of $C$ ôte d'Ivoire. N. Engl. J. M ed. 355, 1141-1153 (2006).

4. Rosen S, Sannel, Collier A, Simon JL: Rationing antiretroviral therapy for HIV/AIDS in Africa: choices and consequences. PL oS M ed. 2, e303 (2005).
5. Bentwich Z, Kalinkovich A, Weisman Z: Immune activation is a dominant factor in the pathogenesis of African AID S. Immunol. Today 16, 187-191 (1995).

6. Fincham J: Could control of soiltransmitted helminthic infection influence the H IV/AID S pandemic. Acta Trop. 86, 315-333 (2003).

7. Borkow G, Bentwich Z: Chronic immune activation associated with chronic helminthic and human immunodeficiency virus infections: role of hyporesponsiveness and anergy. Clin. M icrobiol. Rev. 17, 1012-1030 (2004).

8. Walson JL, John-Stewart G: Treatment of helminth co-infection in H IV-1 infected individuals in resource-limited settings. Cochrane D atabase Syst. Rev. 1, CD 006419 (2008).

9. Kallestrup $P$, Zinyama R, G omo E et al.: Schistosomiasis and HIV-1 infection in rural Zimbabwe: effect of treatment of schistosomiasis on CD 4 cell count and plasma H IV-1 RN A load. J. Infect. D is. 192, 1956-1961 (2005).

10. Nielsen $N O$, Simonsen $P E, D$ algaard $P$ et al.: Effect of diethylcarbamazine on H IV load, CD $4 \%$, and CD 4/CD 8 ratio in HIVinfected adult Tanzanians with or without lymphatic filariasis: randomized doubleblind and placebo-controlled cross-over trial. Am. J. Trop. M ed. H yg. 77, 507-513 (2007).

11. Walson JL, $O$ tieno PA, M buchi $M$ et al.: Albendazole treatment of H IV-1 and helminth co-infection: a randomized, double blind, placebo-controlled trial. AID S (2008) (In Press).

12. M underi $P, M$ utuluuza $C$, Reid $A$, Walker $A$ : $C D 4$ response to HAART in previously untreated adults with HIV infection in Africa: The D ART Trial. Presented at: Conference on Retroviruses 0 pportunistic Infections. San Francisco, CA, USA, 8-11 February, 2004 (Abstract 592). 
13. Gupta SB, Jacobson LP, M argolick JB et al.: Estimating the benefit of an H IV-1 vaccine that reduces viral load set point. J. Infect. Dis.195, 546-550 (2007).

14. Q uinn TC, Wawer MJ, Sewankambo N et al.: Viral load and heterosexual transmission of human immunodeficiency virus type 1. Rakai Project Study G roup. N. Engl. J. M ed. 342, 921-929 (2000).

15. Gallagher $M, M$ alhotra I, M ungai PL et al.: The effects of maternal helminth and malaria infections on mother-to-child H IV transmission. AIDS 19, 1849-1855 (2005).

16. Nacher $\mathrm{M}, \mathrm{C}$ arme $\mathrm{B}$, Couppié P: HIV and immune reconstitution disease in the wormy world. AID S 22, 546 (2008).
17. Borkow G, Bentwich Z: Eradication of helminthic infections may be essential for succesfful vaccination against HIV and tuberculosis. Bull. World H ealth O rgan. 78, 1368-1369 (2000).

18. Lawn SD, Butera ST, Folks TM : Contribution of immune activation to the pathogenesis and transmission of human immunodeficiency virus type 1 infection. Clin. Microbiol. Rev. 14, 753-777 (2001).

Affiliations

- Judd L Walson, M D, M PH University of Washington, D epartment of M edicine, Seattle, WA, USA and,

Kenya M edical Research Institute (KEM RI), Centre for Clinical Research, N airobi, Kenya Tel.: +1 206543 4278;

Fax: +1 206543 4818;

walson@u.washington.edu

- Benson $O$ Singa, M BChB, M PH Kenya M edical Research Institute (KEM RI), Centre for Clinical Research, Nairobi, Kenya singab02000@yahoo.com

- Grace John-Stewart, M D, PhD University of Washington,

D epartment of M edicine, Seattle, WA, U SA Tel.: +1 206543 4278;

Fax: +1 206543 4818;

gjohn@u.washington.edu 